\section{ECCOMAS} Proceedia
COMPDYN 2021

$8^{\text {th }}$ ECCOMAS Thematic Conference on Computational Methods in Structural Dynamics and Earthquake Engineering

M. Papadrakakis, M. Fragiadakis (eds.)

\title{
TYPOLOGICAL ANALYSIS AND VULNERABILITY CURVES FOR MASONRY CHURCHES
}

\author{
Elvis Cescatti ${ }^{1}$, Veronica Follador ${ }^{2}$, and Francesca da Porto ${ }^{1}$ \\ ${ }^{1}$ Depart. of Geosciences - University of Padova \\ Via G. Gradenigo, 6, 35131 Padova (IT) \\ elvis.cescatti@dicea.unipd.it; francesca.daporto@unipd.it \\ ${ }^{2}$ DICATAM - University of Brescia \\ Via Branze, 43, 25123, Brescia (IT) \\ v.follador@unibs.it
}

\begin{abstract}
Masonry churches have a high intrinsic seismic vulnerability, demonstrated by the effects of the last earthquakes in Italy. In the present study a database of 1391 II level post-earthquake survey form $(A-D C)$ has been analyzed. The forms were filled by the University of Padua, the University of Naples Federico II and the University of Naples Parthenope, under the coordination of the Department of Civil Protection, the Cultural Heritage Ministry (MiBACT) and the Italian Laboratories University Network of Seismic Engineering (Re-LUIS). The form were filled after the 2016/2017 Central Italy seismic sequence (889 forms), the 2012 Emilia earthquake (264 forms) and after the 2009 L'Aquila earthquake (238 forms). A typological investigation has been done as preliminary phase, and some vulnerability modifiers have been determined, with the aim of developing vulnerability and fragility curves dependent of poor but effective typological characteristics of the buildings.
\end{abstract}

Keywords: Masonry Churches, Definition of Typologies, Vulnerability Curves, L'Aquila 2009, Emilia 2012, Central Italy 2016.

ISSN:2623-3347 (C) 2021 The Authors. Published by Eccomas Proceedia.

Peer-review under responsibility of the organizing committee of COMPDYN 2021.

doi: $10.7712 / 120121.8702 .19026$ 


\section{INTRODUCTION}

In the last decades, great losses have occurred to the artistic and cultural heritage as a result of seismic events. In particular, serious damage has been suffered by churches [1-6], object of the present study. With the purpose of assess the safety conditions and collect the data of the damage suffered by ecclesiastical buildings, a specific form for the survey of damage churches $[7,8]$ was developed. The current version (A-DC form $[9,10]$ ) consists of several sections, in which identification data, context description, damage data, safety evaluations and basic geometric information of the building are reported. As concern the damage survey, the form is based on the identification of the damage level (from 0 to 5) of 28 possible collapse mechanisms of macro-elements. Then, it is possible to obtain an overall damage index $i_{d}$ (from 0 to 1 ) as a normalized average of the damage level of each mechanism.

The seismic events considered in this study are those in which the form for the damage survey of churches has been used in its actual version: the 2009 L'Aquila earthquake, the 2012 Emilia earthquake and the 2016/17 Central Italy seismic sequence. The surveys have been carried out under the coordination of the Department of Civil Protection (DPC) and the Ministry of Cultural Heritage and Tourism (MiBACT) by group of technicians (structural engineers, officials of the superintendence, fireman if the safety level was low). In particular, the authors have used A-DC forms filled mainly by the University of Padua, and in part by the University of Naples Federico II and the University of Naples Parthenope.

Churches are a peculiar type of building which has intrinsic seismic vulnerability due to its constructive and typological features (i.e. great lights, absence of intermediate diaphragms, large height to width ratio of walls, thrusting horizontal structures) [11]. Thus, in order to elaborate large-scale analysis, churches must be approached differently than ordinary buildings [2, $13,14]$. Usually, the evaluation of seismic risk at territorial scale requires the identification of different classes of buildings which have similar behavior [12]. For ordinary buildings, those classes are generally defined by the type of load-bearing structure (e.g. masonry, reinforced concrete, etc.) and by the constructive techniques and building regulations (mainly identifying with age of construction ranges). On the other hand, churches are usually load-bearing masonry buildings, distinguished by typological features more than constructive ones (e.g. presence of macro-elements, type of plan and façade, etc.). Therefore, the aim of this work is to identify typological characteristics that affect the vulnerability of the churches, in order to allow the elaboration of typological vulnerability and fragility curves that could account for different churches vulnerabilities and therefore be applied on large-scale seismic risk assessment according to the churches features.

\section{TYPOLOGICAL DESCRIPTION OF THE SAMPLE}

The database considered in the present study includes a total of 1391 post-earthquake survey A-DC forms [9, 10], filled mainly by the University of Padua, and in part by the University of Naples Federico II and the University of Naples Parthenope. Of these, 889 were collected following the 2016/2017 Central Italy earthquake sequence [6], 264 following the 2012 Emilia earthquake [4], and finally 238 following the 2009 L'Aquila earthquake [3]. Table 1 shows the geographical distribution of the surveys.

As already mentioned, in order to carry out the vulnerability analysis of churches it is necessary to consider the great geometrical and typological differences that they may present, which could lead to a very different seismic response. In particular, using the information collected from the A-DC forms and the photos of the post-earthquake surveys, the typological distributions of the churches affected by the three 2009, 2012 and 2016/17 earthquakes have been analyzed. 


\begin{tabular}{ll} 
Earthquake & Regions (number of churches): province \\
\hline Central Italy 2016/17 & Marche (602): Ancona (AN), Ascoli Piceno (AP), Fermo (FM), Macerata \\
& (MC), Pesaro e Urbino (PU) \\
& Abruzzo (111): L'Aquila (AQ), Chieti (CH), Pescara (PE), Teramo (TE) \\
& Umbria (110): Perugia (PG), Terni (TR) \\
& Lazio (66): Frosinone (FR), Rieti (RI), Viterbo (VT) \\
& Emilia Romagna (138): Bologna (BO), Ferrare (FE), Modena (MO), Reggio \\
& Emilia (RE) \\
& Lombardia (82): Cremona (CR), Mantova (MN) \\
& Veneto (44): Rovigo (RO) \\
\hline L'Aquila 2009 2012 & Abruzzo (238): L'Aquila (AQ), Teramo (TE) \\
\hline
\end{tabular}

Table 1: Geographical distribution of the sample.

Specifically, the distribution of the following database parameters was studied [6]: a) type of plan (Figure 1); b) type of façade; c) masonry type; d) type of bell structure; and e) dimensions (volume).

The results in terms of the distribution of the analyzed features are collected in Table 2 and the typologies associated with each church belonging to the database, geographically located, are presented in Figure 2.

As regards to the type of plan, seven types were identified based on the number of naves, the presence of apse, transept and side chapels (Figure 1). Specifically: type 1 represents one nave churches with, simple rectangular plan, without apse or aggregated elements; type 2 is similar to type 1, with the addition of the apse; type 3 represents the most complex possibility for one nave churches (apse, transept and/or side chapels); type 4 is three or more naves church, with very complex plan (transept, chapels, apses at the end of naves and transept); type 5 is also a three or more naves church, with medium complex plan; type 6 represents the less complex typology of three naves churches (includes also the 2 naves churches); type 7 is circular or central plan (polygonal) church.

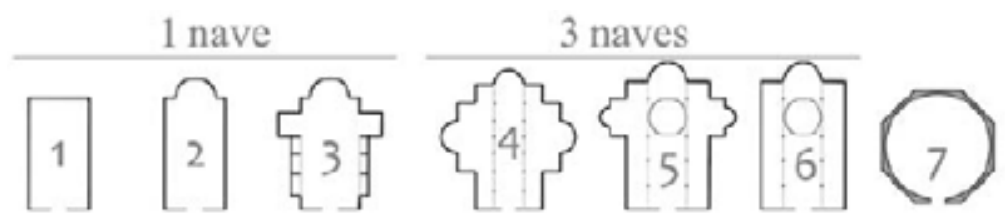

Figure 1: Schematic representation of the seven type of plan considered in this study.

The analysis of the sample showed that in Central Italy simpler churches are predominant. The most common types are 1 and 2, whereas with very small percentages are found types 3,5 and 6; types 4 and 7 are just over 1\%. Table 2 and Figure 2 show that the churches affected by the 2009 L'Aquila earthquake have many similarities with the ones of the 2016/17 Central Italy seismic sequence (both affect the central Apennine belt). In fact, the most widespread are type 1 and 2 churches ( $82.8 \% \mathrm{CI}$ and $66.9 \% \mathrm{AQ})$, but also, type 6 and type 3 are common. The trend identified in the Central Italy region changes considerably for the churches located in the Po Valley: the percentage of type 1 is very small (mostly oratories and minor private chapels). Instead, the more complex typologies (type 3, 6 and 5) are more widespread with a cumulative percentage of $61.4 \%$. The numbers of types 4 and 7 remain marginal. Analyzing the geographical distribution, it can be observed that in the Apennine region there is a predominance of single nave churches (mainly typologies 1 and 2); the cases of churches with more naves are located in the less mountainous areas and in Abruzzo, and they belong to typology 6, so they 
have a not excessively complex geometry. In the Po Valley the typologies present are distributed in the territory, and are not visibly dependent on geographical location.

The second feature analyzed is the type of façade. Four main types of façade have been identified: gabled, salient façade, quadrangular and polygonal. The cases that was not possible to trace back to one of these four types (e.g. churches with side entrances connected to adjacent buildings on several sides or churches with a large prothyrum or narthex) were excluded from the present analysis, because of the different seismic behavior of the façade macroelement.

With regard to the sample of Central Italy, there is a clear majority of gabled type, whereas the church façades of the L'Aquila earthquake belong in large part to the gabled and the quadrangular type. Instead, most of the churches in the Po Valley have salient and gabled façades.

The type of façade seems to have no correlation with geographical location (Figure 2) probably due to similar geographical conditions of the inspected area all enclosed in the plain.

Another important typological characteristic is the masonry type. Since the masonry texture is often covered by plaster, it is not always possible to determine the constituent material of the walls, unless more in-depth investigations are carried out. As for the façade, also for the masonry typology, the not identified cases have been excluded from the typological analysis.

Four masonry types have been distinguished: random stone, stone ashlar, brick masonry and mixed stone and brick masonry. The masonry parameter distribution is the most clearly readable: in Central Italy and L'Aquila samples, stone is the most common material (mainly random rubble), whereas in Emilia no cases of stone masonry but an almost totality of brick masonry have been identified. Figure 2 shows that the type of masonry depends almost exclusively on the geographical/topographical location. In the lowland areas and in the coastal strip only brick masonry (or mixed masonry at most) is present, whereas rising to a higher altitude and moving away from the coast, bricks begin to be flanked by the stone until it is completely replaced by it (this is particularly evident in the Central Italy earthquake).

Regarding the type of bell tower, four types have been identified: isolated bell tower, bell tower integrated or partially integrated with the church structure, bell gable and absence of bell tower. The samples of Central Italy and L'Aquila have similar distributions: the most common types are integrated bell tower and bell gable, whereas isolated bell tower is very uncommon. L'Aquila sample has also a $10 \%$ of cases in which the bell tower is absent. Also, for this parameter, the Emilia database is visibly different from the others, presenting for the most part integrated and isolated bell tower, and only few cases of bell gable. Figure 2 shows that, in this case, the differences between the distributions of the samples depend more on the territorial/regional area, rather than on altimetric or topographical factors.

The last of the typological features analyzed is the volume of the church. Since many forms were incomplete in the section related to the geometric survey, also this parameter is not identified for the all database. Six ranges of volume have been chosen: two ranges of very small and small churches (from 0 to 250 and from 250 to $500 \mathrm{~m}^{3}$ ), two of medium size churches (from 500 to 1000 and from 1000 to $2500 \mathrm{~m}^{3}$ ) and two ranges of large churches (from 2500 to 5000 and from $5000 \mathrm{~m}^{3}$ upwards). Table 2 shows that in Central Italy and L'Aquila the most widespread churches are those of medium size, followed by small churches and lastly those of large size. Instead, in Emilia, the most of the churches have a large or medium volume. From a territorial distribution point of view, large churches are typically located in lowland areas or in correspondence of cities or important centers (Figure 2). 
Elvis Cescatti, Veronica Follador and Francesca da Porto

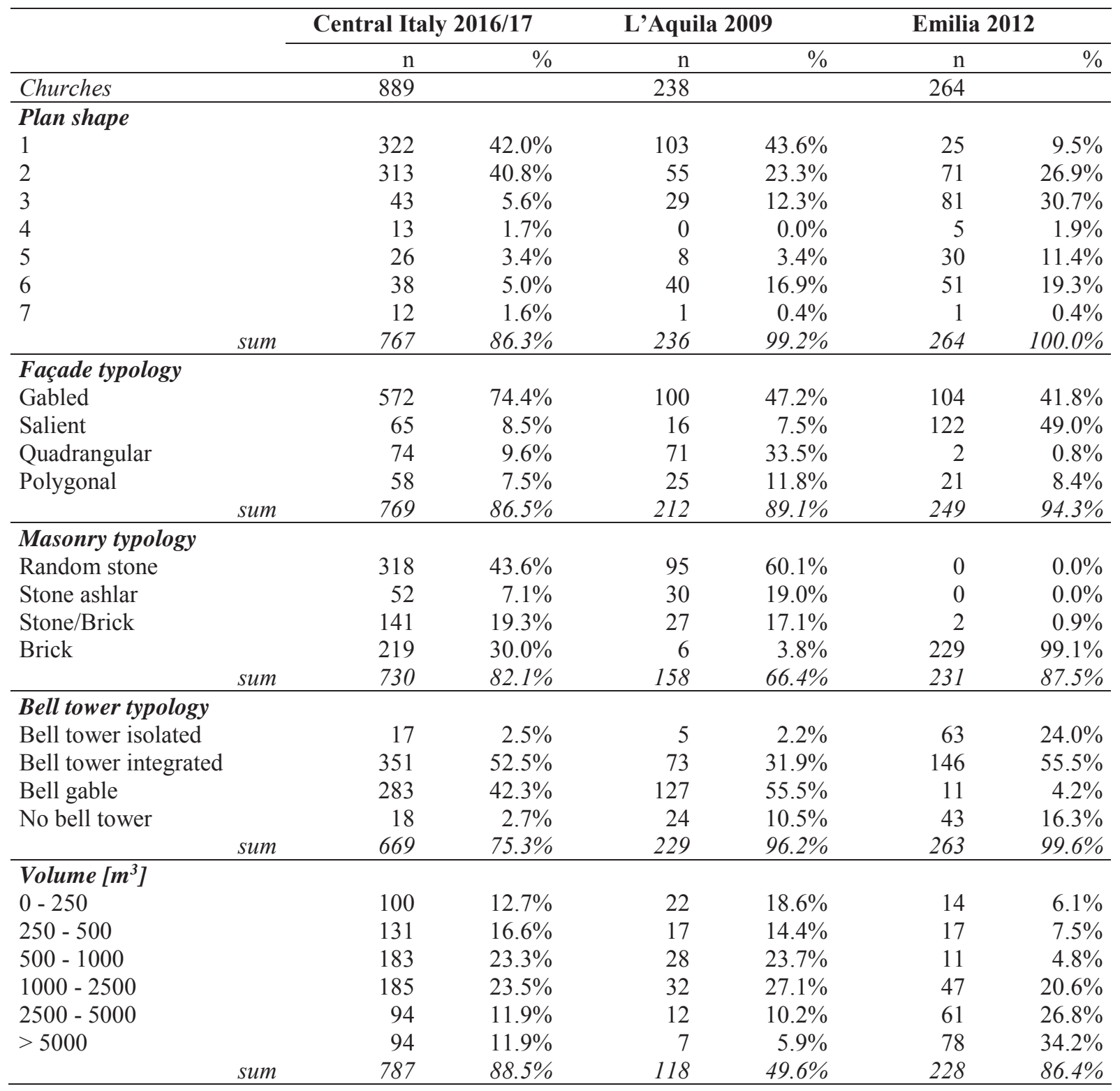

Table 2: Statistical distribution of plan shape, façade type, masonry type, bell tower typologies and volume for the earthquake of Central Italy 2016/17, L’Aquila 2009 and Emilia 2012.

It can be concluded that Emilia churches are typologically very different from Central Italy and L'Aquila ones. The latter, belonging to the same geographical area, have more homogeneous characteristics, with some differences due to the proximity to the coast and to altimetric/topographical factors. In particular, the feature that the most depends on altitude is the masonry type, as a direct consequence of the availability of the different materials on site. The other parameters analyzed are not directly dependent on the altimetry, but are more related to the territorial/regional building traditions, especially evident in the type of façade and bell tower.

In summary, it emerges that the churches of Central Italy are mainly simple, medium size and single nave, with a gabled façade and a bell gable or a bell tower integrated into the structure of the church, built in stone (mostly random) in the Apennine area and brick in the coastal strip. Very similar are the churches affected by the L'Aquila earthquake, with the only difference that prefer a quadrangular façade and the cases with more than one nave are more widespread, although maintaining a very simple plan. Very different are the churches of Emilia and the Po 
Valley regions, which have large complex plans with gabled or salient façades, with the presence of isolated or integrated bell tower and built almost exclusively in brick.

To compare several features, the maps in Figure 2 show that in Emilia there is a good correspondence between volume and complexity (typology of plan shape), whereas in Central Italy even when the churches are large the complexity is never high (particularly evident on the coastal strip).

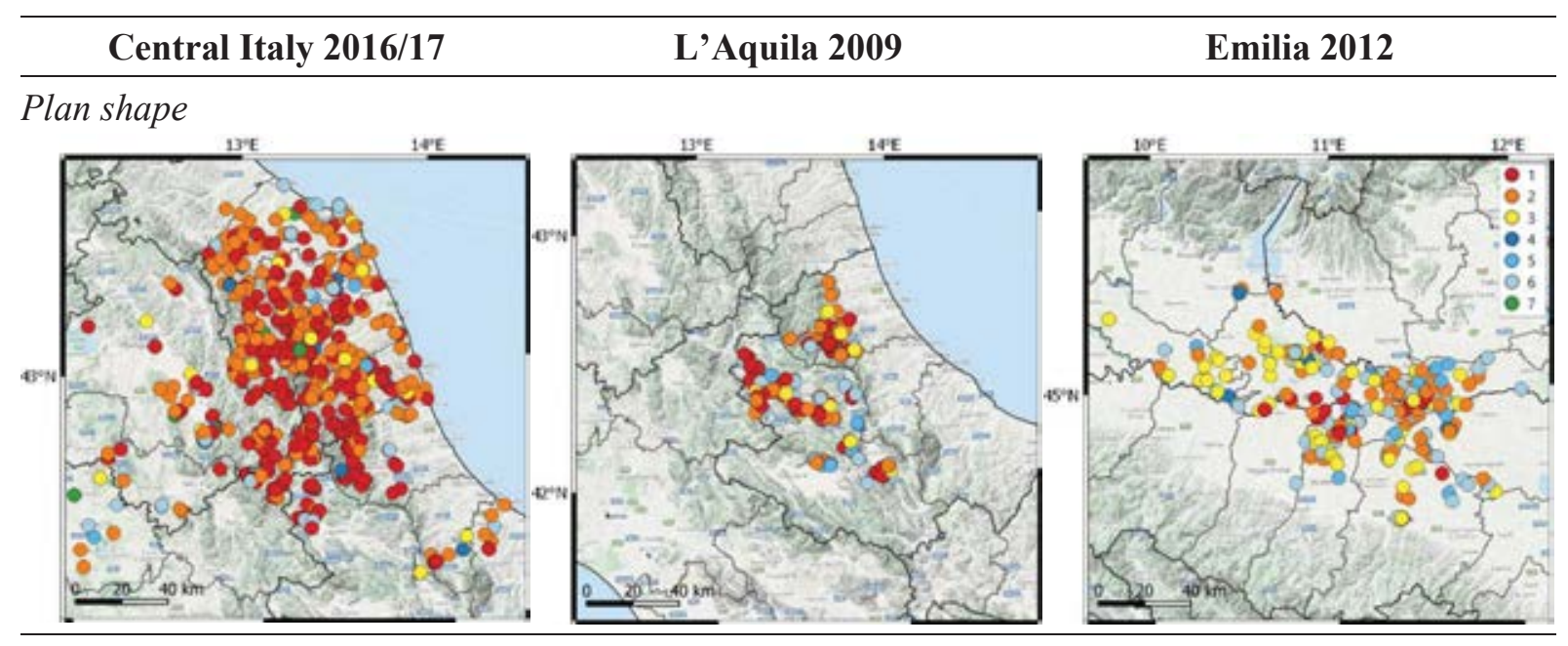

Façade typology
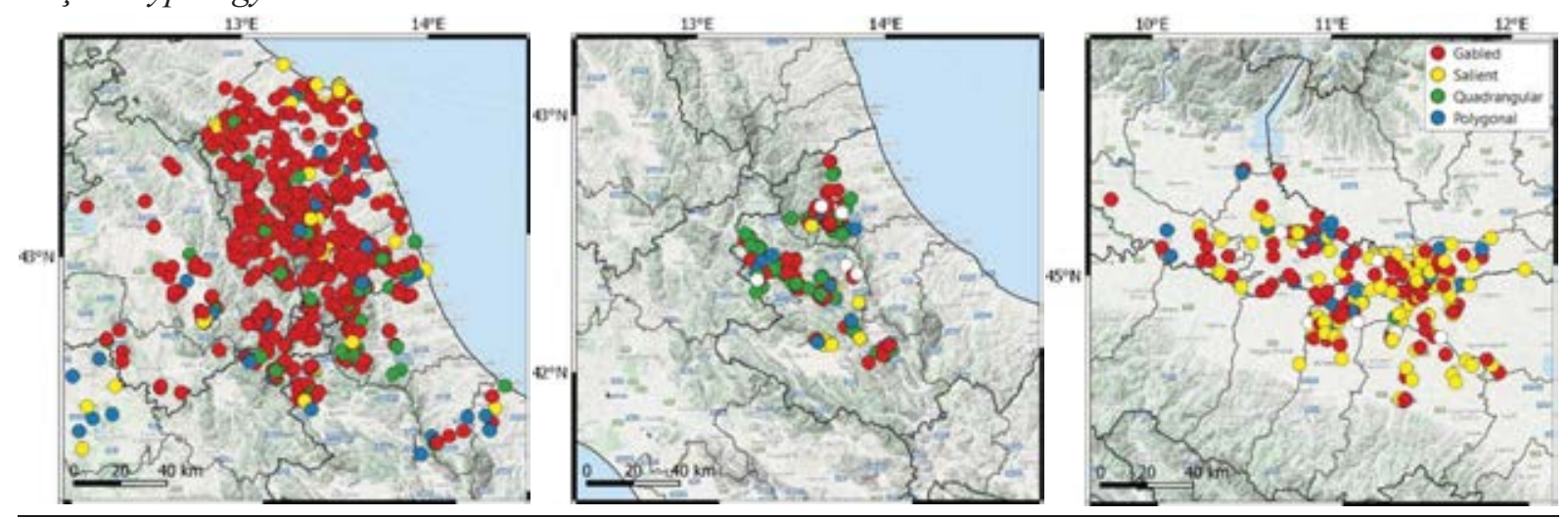

Masonry typology
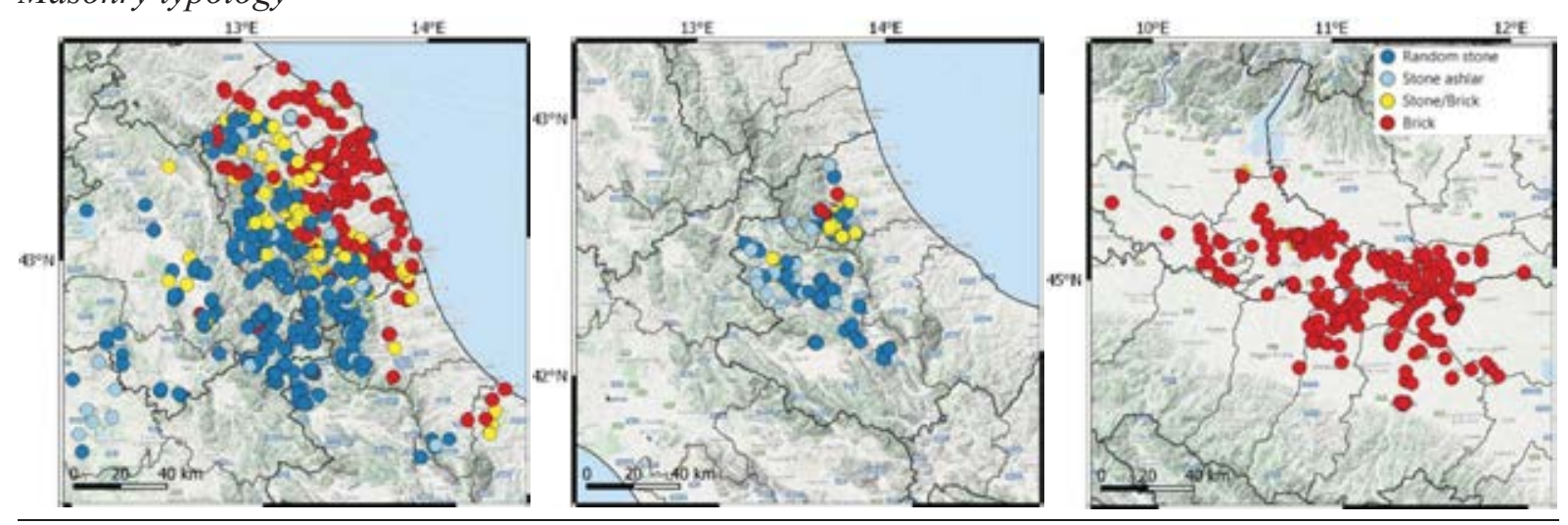

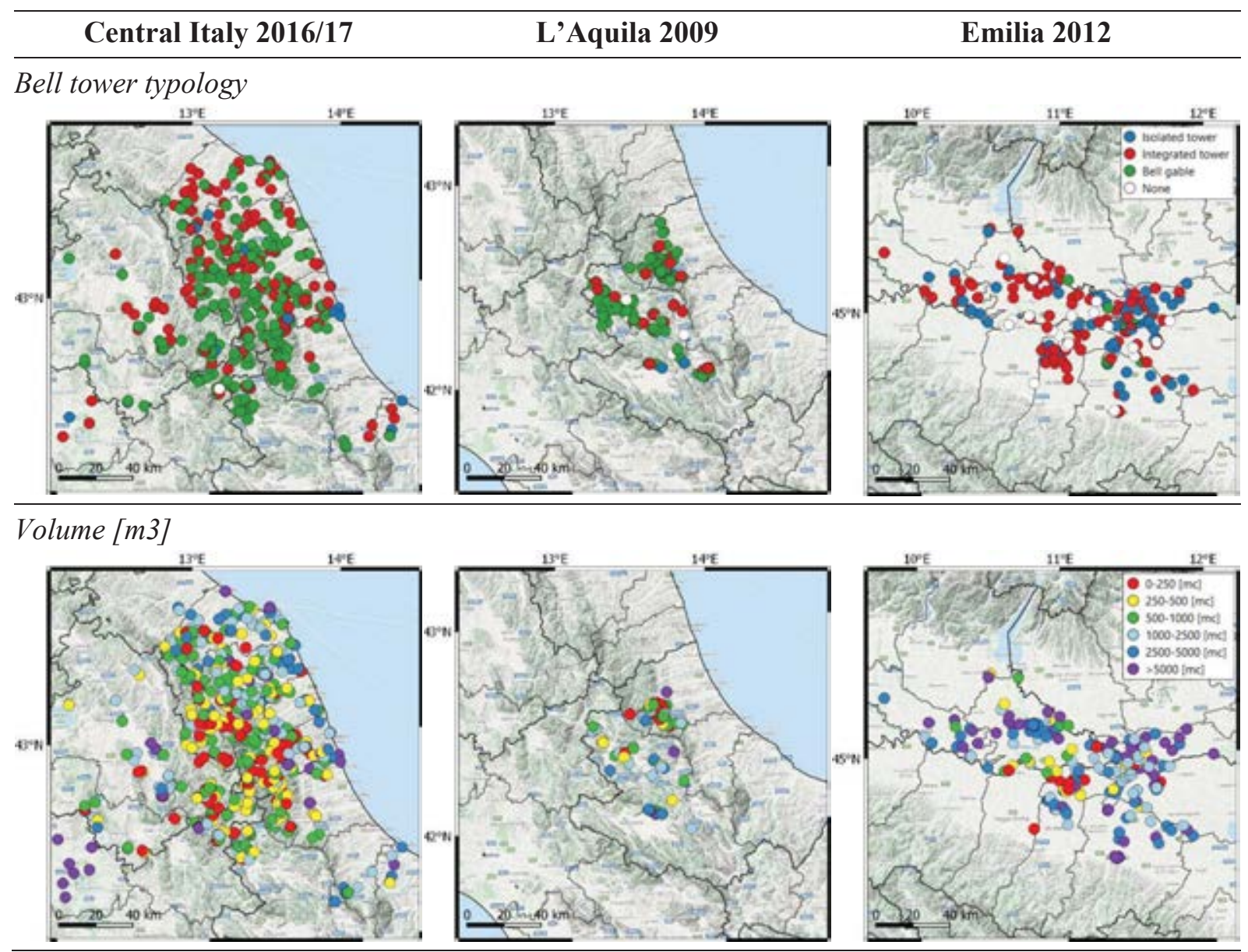

Figure 2: Map of the geographical distribution of different typological features for the earthquake of Central Italy 2016/17, L’Aquila 2009 and Emilia 2012.

\section{VULNERABILITY CURVES}

The seismic vulnerability of a building is defined as the propensity of the structure to suffer damage after a seismic event of a given intensity. It could be represented by a continuous function called vulnerability curve that relates the expected mean value of damage of a class of buildings to the seismic intensity. The latter is usually presented in terms of macroseismic intensity, but it can also be provided as peak ground acceleration-PGA values.

The formulation originally provided by [15] for residential buildings and further adapted to churches by Lagomarsino and Podestà [13] (1) was take as reference to develop typological vulnerability curves.

$$
\mu_{d}=2,5\left[1+\tanh \left(\frac{I+3.4375 \cdot \overline{l_{v}}-8.9125}{q}\right)\right]
$$

where $\mu_{d}$ represents the mean damage grade $\left(0 \leq \mu_{d} \leq 5\right)$ as function of: the macroseismic intensity $I$ expressed in accordance with the MCS scale [16], the mean vulnerability score $i_{v}$ derived from the second level survey form for churches [17], and the ductility index $q=3$.

In particular, a fitting procedure of the observational damage data collected was carried out using (2):

$$
\begin{gathered}
\mu_{D}=2,5 \cdot\left[1+\tanh \left(\alpha \cdot I_{M C S}+\beta\right)\right] \\
\text { with } \quad \alpha=1 / q
\end{gathered}
$$




$$
\text { and } \beta=a \cdot i_{v}+b
$$

and optimizing the value of $\alpha$ and $\beta$.

The formulation (2) is equivalent to (1), but expressed in terms of the two parameters $\alpha$ (3) and $\beta(4)$,. In this way, from the fitting procedure on mean damage values, the resulting vulnerability curve inherently includes the average value of $i_{v}$ on the whole dataset. Indeed, as suggested below, the evaluation of different vulnerabilities classes or typologies could be related to a selected subset of homogenous churches.

\subsection{Consideration on the damage index $i_{d}$}

As mentioned before, the A-DC survey form allows to calculate an overall damage score (damage index) $i_{d}$ for each church. In particular:

$$
i_{d}=\frac{1}{5} \frac{\sum_{k=1}^{n} d_{k}}{n}
$$

where $n$ is the number of mechanisms that can be potentially activated in the church and $d_{k}$ is the damage recorded in the $k$-th mechanism (from 0 to 5).

In order to be used for vulnerability and fragility analysis, the damage index $i_{d}$ has to be converted to a damage level from 0 to 5, according to the EMS scale [18]. One of the most used correlation [13] is reported in Table 3.

\begin{tabular}{lcccccc}
\hline Damage index $i_{d}$ & $0-0.05$ & $0.05-0.25$ & $0.25-0.4$ & $0.4-0.6$ & $0.6-0.8$ & $0.8-1$ \\
\hline $\begin{array}{l}\text { Damage level } \\
\text { (EMS98) }\end{array}$ & DS0 & DS1 & DS2 & DS3 & DS4 & DS5 \\
\hline $\begin{array}{l}\text { Description of the } \\
\text { damage }\end{array}$ & no damage & $\begin{array}{c}\text { slight } \\
\text { damage }\end{array}$ & $\begin{array}{c}\text { moderate } \\
\text { damage }\end{array}$ & $\begin{array}{c}\text { heavy } \\
\text { damage }\end{array}$ & $\begin{array}{c}\text { very heavy } \\
\text { damage }\end{array}$ & collapse \\
\hline
\end{tabular}

Table 3: Correlation between the damage index id of the A-DC form and the damage level according to the EMS98 scale [13].

Using the correlation in Table 3, a process of discretization of a continuous quantity is carried out. This process is required to relate the result of the A-DC form to a damage level and to build damage probability matrices (DPM), but inevitably, it implies a great loss of detail. Moreover, this discretization slightly varies the overall mean description of the damage. For instance, considering a dataset of 101 churches equally distributed in the damage index $i_{d}$ from 0 to 1 , due to the different dimensions of each damage state, that discretization leads to an average $\mu_{D}$ damage of 2.87 instead of the mathematical mean of 2.50. Figure 3 reports the real case of the 2016/17 Central Italy database with $i_{d}$ multiplied by 5 to have a comparison. The graph shows how different the damage results can be: as expected, in general the mean damage obtained through the correlation proposed by Lagomarsino and Podestà [13] is higher then that obtained directly by the damage index $i_{d}$, but not in a consistent way. Indeed, in correspondence of some intensities (e.g $\mathrm{I}_{\mathrm{MCS}}=8$ and $\mathrm{I}_{\mathrm{MCS}}=9.5$ ) the difference is very low (about 0.15 ), while for others (e.g $\mathrm{I}_{\mathrm{MCS}}=7.5, \mathrm{I}_{\mathrm{MCS}}=8.5$ and $\mathrm{I}_{\mathrm{MCS}}=10$ ) the difference is very impacting (0.5). This is a consequence of the specific distribution of the sample, and therefore it can generate unreliable results in terms of comparison analysis. 


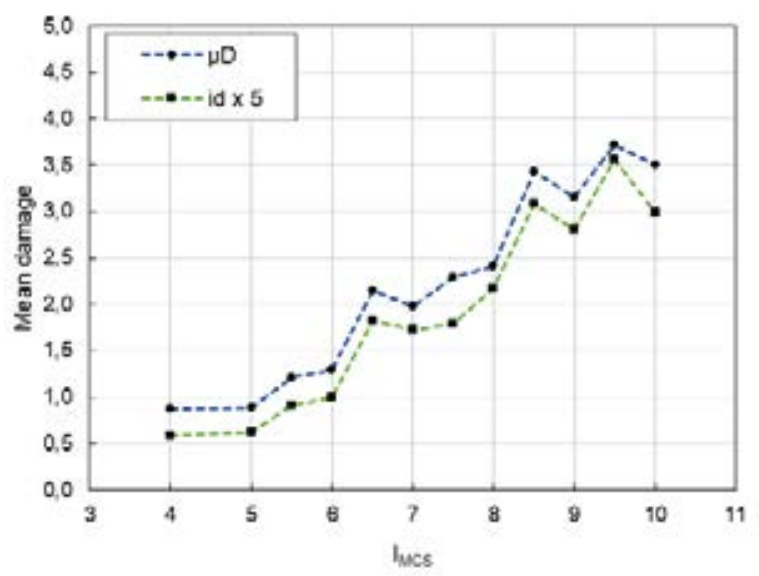

Figure 3: Comparison between the mean value of the damage expressed in terms of $\mu_{D}$ and $i_{d}$ for the Central Italy churches.

Therefore, since this study works directly on the average damage to figured out the vulnerability curve, and does not use the DPMs, it was decided to build the vulnerability curve in terms of damage index, using in place of the usual mean value $\mu_{d}(2)$ the average $i_{d}$ values (6):

$$
i_{d}=0,5\left[1+\tanh \left(\alpha \cdot I_{M C S}+\beta\right)\right]
$$

The value of 2.5 is assumed as 0.5 accordingly to the domain of $i_{d}$. This choice has been made both to have more possibilities to adapt the curve to the observational values, and to use in a direct way the information obtained from the damage surveys, avoiding the loss of information deriving from the discretization of the value of $i_{d}$.

\subsection{Fitting procedure}

Once defined the formulation (6), some specification about the adopted fitting procedure are herein reported.

The two coefficients $\alpha$ and $\beta$ have been calibrated with the minimization of the total error. The ductility related coefficient $\alpha$ was not keep fixed to $q=3$ since the observation of three different earthquakes and an extended sample shows a variability of this factor as reported in Table 4. As concern the $\beta$ parameter, it was derived by the mean value of the observational damage indices of the A-DC forms, with a fitting procedure based on the minimization of the total error resulting from the sum of the square residual.

Table 4 reports values obtained from the fitting of eq. (6) and Figure 4 plot each vulnerability curve on the experimental data observed. As is possible to notice there is a good agreement between the observed data and the continuous curves with very limited errors.

\begin{tabular}{cccc} 
& Central Italy 2016/17 & L'Aquila 2009 & Emilia 2012 \\
\hline$\alpha$ & 0.263 & 0.316 & 0.360 \\
$\beta$ & -2.205 & -2.678 & -2.471 \\
\hline error & $9.86 \times 10^{-04}$ & $4.83 \times 10^{-04}$ & $1.82 \times 10^{-03}$ \\
\hline$q$ & 3.807 & 3.161 & 2.778 \\
\hline
\end{tabular}

Table 4: Value defined for the three analyzed earthquakes according to eq. (6) 

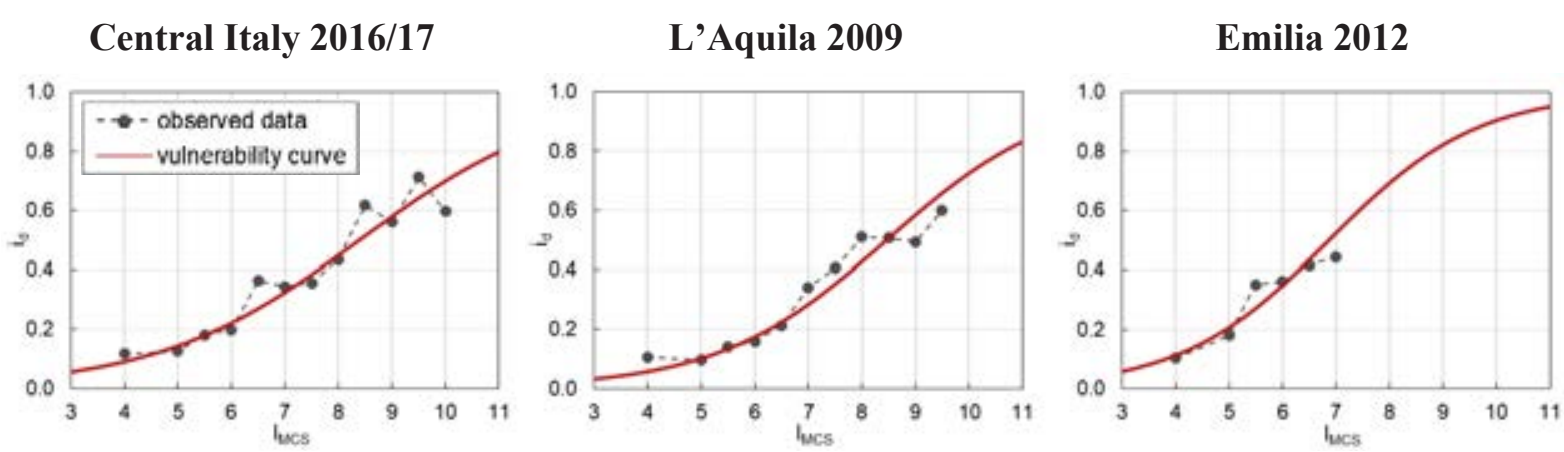

Figure 4: Vulnerability curves obtained from the three analyzed earthquakes

\section{INFLUENCE OF TYPOLOGIES}

Since the previously observed curves are defined on the whole dataset, hence accounting for the average vulnerability, the selection of homogenous dataset of churches with the same vulnerability may improve the overall evaluation.

Once defined the vulnerability model and the fitting method, it was possible to analyze the influence on seismic vulnerability of different typology characteristics that may lead to the homogenous subset above seek. Specifically, in this paper, the influence of masonry type and the number of naves are presented.

On the basis of the results reached in section 2 about the typological distribution of the churches belonging to the database, the following analyses have been carried out limited to the churches of Central Italy and L'Aquila, in order to guarantee the uniformity of the sample. Future more accurate analysis will allow to study the entire database, and come to overall results not affected by possible errors due to not considered features.

\subsection{Influence of masonry type}

The first typological parameter to be analyzed is the type of masonry. The categories already identified in the context of typological characterization have been further simplified and reduced to three: stone masonry (both ashlar and random rubble masonry), brick masonry and mixed stone and brick masonry.

Figure 5a shows that the two extreme categories (i.e. stone masonry and brick masonry) have a marked difference in terms of damage, whereas the behavior of the intermediate one (i.e. mixed masonry) seems to be less linear and tends to overlap with the former in correspondence of some $\mathrm{I}_{\mathrm{MCS}}$. This can be attributed to the great variability that mixed masonry can presents, sometimes with a predominance of stone, sometimes of brick. Moreover, it is possible that in some cases the particular disposition of the different materials composing the masonry leads to both particularly unfavorable and favorable consequences.

Therefore, this parameter proves to be relevant for the definition of seismic vulnerability. In Figure $5 \mathrm{~b}$ the results of the fitting procedure are shown. In this elaboration, the behavior of mixed masonry churches emerges to be very similar to stone masonry ones, although those constructed in brick masonry proves to have a much better response to seismic actions. 


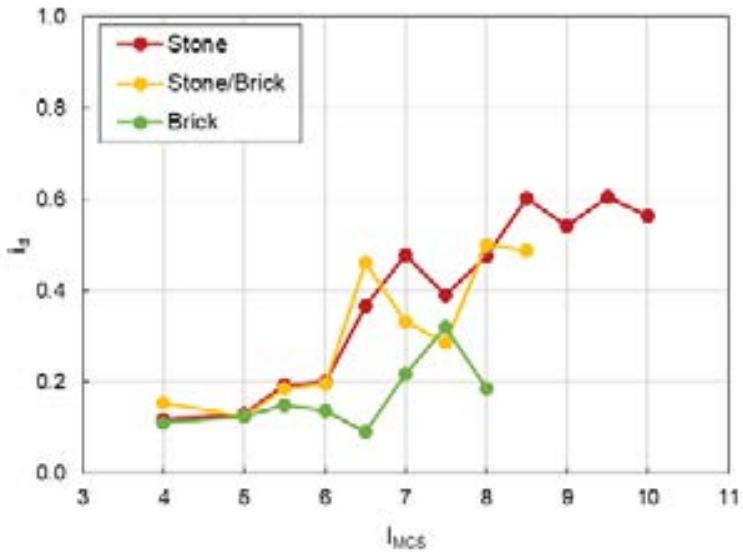

a)

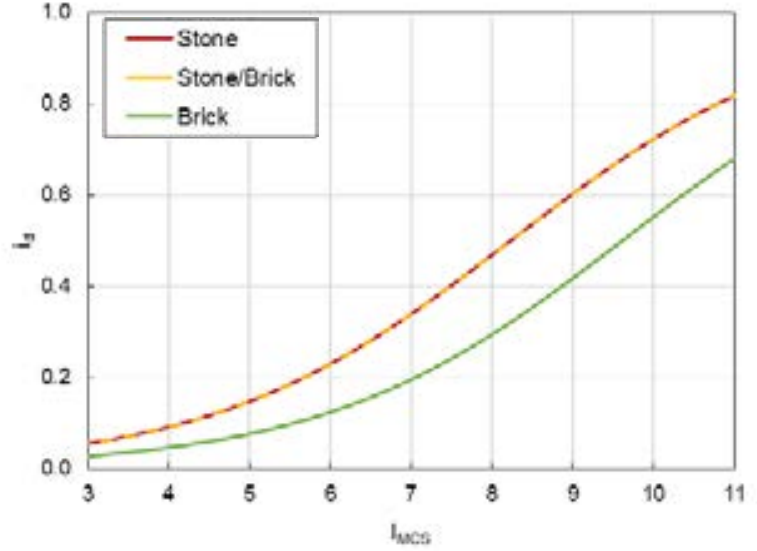

b)

Figure 5: Mean $i_{d}$ values for stone, mixed (stone/brick) and brick masonry churches (a) and resulting vulnerability curves (b).

\subsection{Influence of number of naves}

The number of naves is the second typological feature analyzed. In particular, two classes were defined $[19,20]$ : one nave churches and more than one nave.

Figure 6a shows that for low value of $\mathrm{I}_{\mathrm{MCS}}$ the damage observed for the two classes is similar. Then, with the increase of the intensity, the different behavior of the different types clearly emerges: churches with more than one nave tend to be less vulnerable compared to those with one nave. The different vulnerability is justified by the greater possibility of churches with several naves to absorb horizontal forces, thanks to the presence of colonnades and more widespread connections. On the other hand, the presence of such elements also makes less likely that all of them are damaged in a marked way; in fact, as the complexity increases, the weight of each macro-element decreases on the overall evaluation of the damage, leading on lower damage indices.

In Figure 6b, the vulnerability curves calibrated on the observed damage of both one and more than one nave churches.

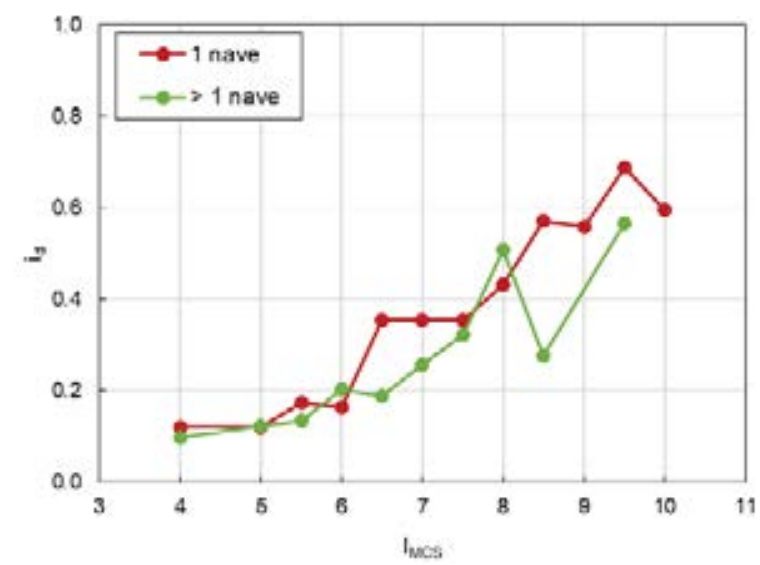

a)

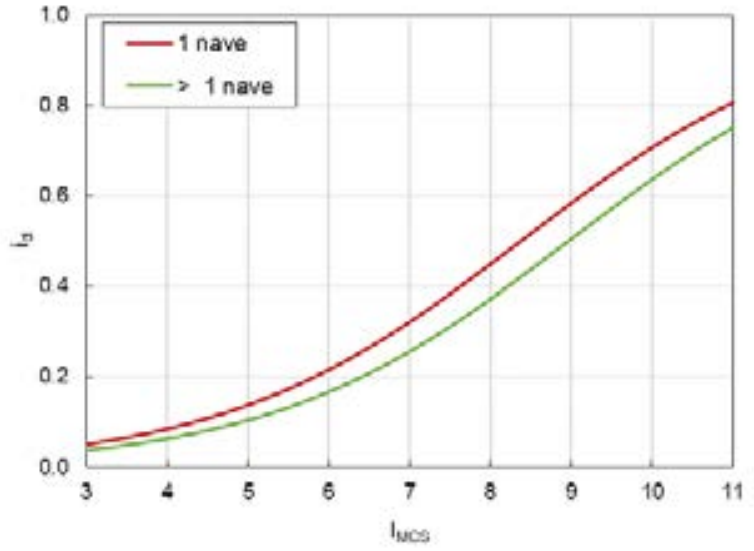

b)

Figure 6: Mean $i_{d}$ values for one nave and more than one nave churches (a) and resulting vulnerability curves (b). 


\section{CONCLUSIONS}

- The present paper has presented a detailed typological distribution analysis of 1391 churches, affected by the 2009 L'Aquila earthquake, the 2012 Emilia earthquake and the 2016/17 seismic sequence of central Italy. The considered features have been plan shape, type of façade, masonry type, typology of bell tower, and volume of the church. It was figured out that the greater differences are due to the geographical and the altimetric/morphological location. In particular, churches of Central Italy regions are mainly simple, medium size and single nave, with a gabled or quadrangular façade and a bell gable or a bell tower integrated into the structure of the church, built in stone (mostly random) in the Apennine area and brick in the coastal strip. On the contrary, the churches located in the Po Valley regions generally have large complex plans with gabled or salient façades, with the presence of isolated or integrated bell tower and built almost exclusively in brick.

- Then, a methodology to derive vulnerability curves from damage data collected by the ADC survey forms were defined starting form [13] and adapting the formulation to large scale and typological evaluation needs. Specifically, a reflection on the relation between the damage index $i_{d}$ and the discrete damage value $\mu_{d}$ was made and the vulnerability curves for the three analyzed earthquakes were provided.

- Lastly, the impact on seismic vulnerability related to the type of masonry and the number of naves of the churches was analyzed. Three different masonry typologies were defined (i.e. stone masonry, brick masonry and mixed stone and brick masonry), with the result that stone masonry and mixed masonry churches have a similar vulnerability, significantly higher than the one of brick masonry churches. Regarding the number of naves, one nave churches result more vulnerable of more than one nave ones, probably thanks to the presence of colonnades and widespread connections.

- Possible future developments are, first of all, the analysis of the influence of more typological parameters on the seismic vulnerability of churches. Then, an important further study is the extension of the procedure to the overall database, inclusive of Emilian churches.

\section{ACKNOWLEDGEMENTS}

Special thanks are due to the Italian Department of Civil Protection (DPC), which funded this study in the framework of the ReLUIS-DPC Project 2019-2021 - Work Package 4: MARS (MAps of Risk and Scenarios of seismic damage) - Task 8: Models and fragility curves of churches (Modelli e curve di fragilità delle chiese).

\section{REFERENCES}

[1] F. Doglioni, A. Moretti, V. Petrini, P. Angeletti, Le chiese e il terremoto. Dalla vulnerabilità constatata nel terremoto del Friuli al miglioramento antisismico nel restauro, verso la politica di prevenzione. Trieste, Italy, Lint Editoriale Associati, 1994. (in Italian)

[2] S. Lagomarsino, S. Podestà, Seismic Vulnerability of ancient churches: I. Damage assessment and emergency planning. Earthquake Spectra, 20(2), 377-394, 2004 (a). 
[3] F. da Porto, F. Silva, C. Costa, C. Modena, Macro-scale analysis of damage to churches after earthquake in Abruzzo (Italy) on April 6, 2009. Journal of Earthquake Engineering, 16(6), 739-758, 2012.

[4] S. Taffarel, M. Giaretton, F. da Porto, C. Modena, Damage and vulnerability assessment of URM buildings after the 2012 Northern Italy earthquakes. 16th International Brick and Block Masonry Conference (IBMAC 2016), Padua, Italy, June 26-30, 2016.

[5] E. Cescatti, S. Taffarel, A. Leggio, F. da Porto, C. Modena, Macroscale damage assessment of URM churches after the 2016 sequence in Centre of Italy. XVII National Conference on L'Ingegneria sismica in Italia (ANIDIS 2017), Pistoia, Italy, September 1721, 2017. (in Italian)

[6] E. Cescatti, P. Salzano, C. Casapulla, D. Ceroni, F. da Porto, A. Prota, Damages to masonry churches after 2016-2017 Central Italy seismic sequence and definition of fragility curves. Bull Earthquake Eng, 18, 297-329, 2020.

[7] DPC, Survey form for the cultural heritage - damage to churches. G.U. no. 116, 21/05/2001, 2001. (in Italian)

[8] S. Lagomarsino, L. Maggiolo, S. Podestà, Vulnerabilità sismica delle chiese: proposta di una metodologia integrata per il rilievo, la prevenzione ed il rilievo del danno in emergenza. X National Conference on L'Ingegneria sismica in Italia (ANIDIS 2001), PotenzaMatera, Italy, September 9-13, 2001. (in Italian)

[9] DPCM 23/02/2006, Approval of forms for the seismic damage assessment of cultural heritage buildings. G.U. no. 55, 7/03/2006, 2006. (in Italian)

[10] MiBACT, Direttiva 23 aprile 2015, Aggiornamento della direttiva 12 dicembre 2013, relativa alle "Procedure per la gestione delle attività di messa in sicurezza e salvaguardia del patrimonio culturale in caso di emergenze derivanti da calamità naturali. GU Serie Generale n.169 del 23-7-2015, 2015. (in Italian)

[11] S. Lagomarsino, S. Podestà, Damage and vulnerability assessment of churches after the 2002 Molise, Italy, earthquake. Earthquake Spectra, 20(S1), S271-S283, 2004c.

[12] M. Dolce, A. Prota, B. Borzi, F. da Porto, S. Lagomarsino, G. Magenes, C. Moroni, A. Penna, M. Polese, E. Sperenza, Seismic risk assessment of residential buildings in Italy: Methodology overview and main results. Bulletin of Earthquake Engineering, 2020. https://doi.org/10.1007/s10518-020-01009-5

[13] S. Lagomarsino, S. Podestà, Seismic Vulnerability of ancient churches: II. Statistical analysis of surveyed data and methods for risk analysis. Earthquake Spectra, 20(2), 395412, $2004 b$.

[14] A. Penna, C. Calderini, L. Sorrentino, C.F. Carocci, E. Cescatti, R. Sisti, A. Borri, C. Modena, A. Prota, Damage to churches in the 2016 central Italy earthquakes. Bull Earthquake Eng, 17, 5763-5790, 2019.

[15] H. Sandi, I. Floricel, Analysis of seismic risk affecting the existing building stock. 10th European Conference on Earthquake Engineering, Vienna, Austria, 28 August - 2 September, 1994.

[16] A. Sieberg, Scala MCS (Mercalli-Cancani-Sieberg). Geologie der Erdbeben, Handbuch der Geophysik, 2(4), 552-555, 1930. 
[17] Italian Ministry of Public Building and Works, G.U. no. 47. 2011, February 26. (suppl. ord. no. 54). Directive of the Prime Minister dated on 9/02/2011, Assessment and mitigation of seismic risk of cultural heritage with reference to the Technical Code for the design of constructions, issued by D.M. 14/1/2008, 2011. (in Italian)

[18] G. Grunthal (ed.), European Macroseismic Scale 1998. Cahiers du Centre Européen de Géodynamique et de Séismologie, Luxembourg, 15, 1998.

[19] G. De Matteis, E. Criber, G. Brando, Damage probability matrices for three-nave masonry churches in Abruzzi after the 2009 L'Aquila earthquake. International Journal of Architectural Heritage, 10(2-3), 120-145, 2016.

[20] G. De Matteis, M. Zizi, Preliminary analysis on the effects of 2016 Central Italy earthquake on one-nave churches. R. Aguilar, D. Torrealva, S. Moreira, M.A. Pando, L.F. Ramos eds. Structural analysis of historical constructions, 18, 1268-1279, RILEM Bookseries. Springer, Cham, 2019. 